\title{
A Fast and Continuous Effect: Kinesio Taping
}

\author{
Erkan KAYA \\ Department of Physical Medicine and Rehabilitation, Mareşal Çakmak Military Hospital, Erzurum, Turkey
}

\section{Dear Editor,}

I read the manuscript by Öncü et al., entitled "Efficacy of Kinesio-taping on Symptoms, Hand Functions, and Hand Grip Strength in Carpal Tunnel Syndrome: A Single-Blind and Randomized Controlled Study", which is published in the 1st supplement of your journal, with great interest. Öncü et al. (1) referred to our study on the efficiency of kinesio taping (KT) in patients with impingement syndrome. However, the efficiency of KT in patients with impingement syndrome is not just limited to the first week, as stated in the study (2). In our study, it was emphasized that KT was more superior to physical treatment modalities during the first week. It was also mentioned that it was a more preferable complementary method than physical treatment modalities owing to its rapid pain-decreasing and function-improving effects. Moreover, the efficiency of KT continued in the following controls. In my opinion, the rapid effect of $\mathrm{KT}$ as a pain killer increases the feeling of confidence between a patient and physician and positively affects patient compliance to the treatment process. Furthermore, I think that the KT technique, which is being increasingly used today, has a rapid and continuous effect not only on impingement syndrome but also on other painful musculoskeletal system diseases.

\section{References}

1. Öncü J, İlişer R, Köymen Yılmaz F, Kuran B. Efficacy of Kinesiotaping on Symptoms, Hand Functions, and Hand Grip Strength in Carpal Tunnel Syndrome: A Single-Blind and Randomized Controlled Study. Turk J Phys Med Rehab 2014;60(Supp. 1):43-51. [CrossRef]

2. Kaya E, Zinnuroglu M, Tugcu I. Kinesio taping compared to physical therapy modalities for the treatment of shoulder impingement syndrome. Clin Rheumatol 2011;30:201-7. [CrossRef]

\section{Author's Reply}

Dear editor,

I thank Kaya et al. (1) for their contribution. Our study is a randomized controlled study that evaluated the efficiency of kinesio taping (KT) in patients diagnosed with idiopathic carpal tunnel syndrome with a 12-week follow-up period (2). The most striking result of our study was that the efficiency of KT continued for 3 months when KT and resting splint were used together, but when KT was used alone, its efficiency was equal to that in the control group at the end of the $3^{\text {rd }}$ month (2). Hence, similar to Kaya et al. (1), we emphasized in our study that KT was effective in the early period. However, because the length of the follow-up period was 12 weeks, it was impossible to address a long-acting effect (2). In addition, in the study of Kaya et al. (1), treatment and follow-up were applied for 2 weeks; KT was found to be superior to local physical treatment modalities in the first week, and the effects of local physical treatment modalities and KT were found to be similar to each other in the second week. Considering these data, it can be suggested that KT is effective in alleviating symptoms and improving functions in patients with shoulder impingement syndrome and idiopathic carpal tunnel syndrome. However, in my opinion, further longterm studies are needed for evaluating the long-acting effect.

Jülide ÖNCÜ, Reşat İLişER, Figen KÖYMEN YILMAZ, Banu KURAN

Clinic of Physical Medicine and Rehabilitation, Şişli Etfal Training and Research Hospital, İstanbul, Turkey

\section{References}

1. Öncü J, İlişer R, Yılmaz FK, Kuran B. Efficacy of Kinesio taping on Symptoms, Hand Functions, and Hand Grip Strength in Carpal Tunnel Syndrome: A Single-Blindand Randomized Controlled Study. Turk J Phys Med Rehab 2014;60(Supp. 1):43-51. [CrossRef]

2. Kaya E, Zinnuroglu M, Tugcu I. Kinesio taping compared to physical therapy modalities for the treatment of shoulder impingement syndrome. Clin Rheumatol 2011;30:201-7. [CrossRef] 